\title{
Analysis of Fractured Weldment of Hadfield Steel
}

\author{
Průcha Vojtěch ${ }^{1}$, Křriž Antonín ${ }^{1}$, Žd'ánský Ondřej², Vnouček Milan ${ }^{1}$ \\ ${ }^{1}$ Faculty of Mechanical Engineering, University of West Bohemia. Univerzitní 22, 30614 Pilsen. Czech Republic. E- \\ mail: vprucha@kmm.zcu.cz,kriz@kmm.zcu.cz, vnoucek@kmm.zcu.cz \\ ${ }^{2}$ Wheelabrator Czech, s.r.o., Za Balonkou 269, 26101 Př́ibram I. Czech Republic. E-mail: ondrej.zdansky@norican- \\ group.com
}

This contribution is divided into two sections. The first one deals with identifying the cause of fracture in a ring, which fractured after weld surfacing. Optical and scanning electron microscopy and hardness testing were employed. Chemical composition was determined using the GDOES and EDX methods. Although weld surfacing has led to fracture in the base material, the actual problem was in the inadequate microstructure of the base material. Microscopic analysis revealed that it was heterogeneous. It contained distinctive segregation bands with bands of complex carbides and pearlite colonies, which are undesirable. The microstructure of this steel should be fully austenitic. In order to remove the heterogeneities, solution annealing was proposed and carried out successfully. The second section of this paper explores the options for revealing the microstructure of Hadfield steel. Etching reagents from the literature and authors' experience were put to test.

Keywords: Hadfield steel, welding of Hadfield steel, etching of Hadfield steel, microstructure of Hadfield steel

\section{Introduction}

Hadfield steel is an austenitic manganese steel known for high wear resistance and toughness. In the as-cast state, its microstructure is characterized by an austenititc matrix (owing to high manganese content $-12 \%$ ) with carbide precipitates (these are present due to high levels of carbon (1.2\%) and carbide formers - Fe, Mn and $\mathrm{Cr}$ ) and small colonies of pearlite resulting from carbon having been rejected from the austenite during cooling. These carbides are found along grain boundaries, in interdendritic areas and within grains. Interdendritic carbides can be fairly massive, particularly at triple points, and are sometimes embedded lamellar carbide regions $[1,2,3]$. The above aspects impair the toughness of this steel. To ensure that components made of this steel are reliable in service, a metallurgist needs to reduce the amount of carbide precipitates and/or change their morphology by means of heat treatment. Usually, austenitic manganese steels are solution annealed at temperatures around $1050^{\circ} \mathrm{C}$ for one hour per inch of thickness, and then water-quenched. This should produce a fully-austenitic microstructure. Manganese steels which contain chromium or vanadium should be solution-annealed as high as $1180^{\circ} \mathrm{C}$. It is because these alloy additions contribute to the stability of the carbides in cast steel. At ordinary solution annealing temperatures, these carbides do not dissolve completely [4].

Austenitic manganese steels are difficult to weld, owing to their high carbon and manganese levels and low thermal conductivity. If they are to be welded, stringent welding procedures must be followed and the process temperature must be monitored. Short weld runs performed in several layers are recommended. Post-weld heat treatment is indispensable. Since welding with oxygen mixtures mostly causes embrittlement, it is not used for Hadfield steel in practice. The preferred welding and cladding method for Hadfield steel is arc welding. To prevent hot cracking, phosphorus level must be kept below $0.03 \%[4,5]$. In welding austenitic manganese steels, the primary concern is to avoid heating of the base material which would lead to embrittlement and carbide precipitation. Hence, pre-heating of the base material is ruled out. Under even the most favourable conditions, one should expect some carbides to form, while at the same time the toughness in the HAZ rarely matches that of the base material. Austenitic manganese steel undergoes work hardening in service which means that a surface which suffered damage and requires repair can be expected to be workhardened. The material in such spots should be removed before welding in order to prevent cracking in the HAZ. Poor thermal conductivity and high thermal expansion of austenitic manganese steels may lead to difficulties, such as steep temperature gradients and residual stresses. While cooling, the weld joint develops severe internal stresses. They can be minimized by applying compressive stress to the weld while it is still hot. This prevent cracks from opening and helps to close them $[4,5]$.

\section{Experiments}

A detailed analysis of a failed weldment was conducted. The ability of several etching reagents to reveal various microstructural constituents was tested. A ring of austenitic manganese steel X120Mn12 had the following dimensions: $270 \mathrm{~mm}$ (outer diameter), $250 \mathrm{~mm}$ (inner diameter) and $15 \mathrm{~mm}$ (thickness). After weld surfacing, it developed a crack which originated in the surface of the base material. A metallographic section through the ring was prepared in accordance with [6]. It was examined using ZEISS Observer.Z1m optical microscope and PHILIPS 30XL ESEM electron microscope which was equipped with an EDX analyzer. A microhardness depth profile was measured. Identities of microstructural constituents were confirmed by microhardness measurement using a Dura Scan 70G5 hardness tester.

\section{Results and discussion}

The micrograph in Fig. 1, which was taken at $25 \times$ magnification, shows fractures in both base material and 
the weld metal. First, the weld joint, the weld metal and the heat-affected zone (HAZ) were inspected. A depth profile of microhardness was measured across the weld metal and the base material. The microhardness plot was without abrupt variations. In the HAZ, no grain coarsening or other significant negative changes in terms of phases were detected. However, several transgranular cracks were found under the overlay, as shown in Fig. 2. Their appearance was that of burnt material. In this region, chemical analysis indicated $1.56 \%$ chromium and $0.74 \%$ nickel. It suggests that these cracks formed in the course of welding. Cracks were also detected in the weld metal. The weld metal was found to contain much less nickel than the recommended type of filler wires for surfacing [7]. Therefore, it can be presumed that the prescribed welding procedure was not followed. As a consequence, cracks formed in the weld metal and in the region beneath the weld overlay. Although it is certain that these deficiencies contributed to fracturing in the base material, its main cause is associated with the base material itself. A detailed analysis of the base material is given below.

The first step involved chemical analysis using the GDOES method. The chemical composition specified in the relevant standard is given in Tab. 1. The results of the chemical analysis are shown in Tab. 2. The actual chemical composition meets the standard, except for $\mathrm{C}$ and $\mathrm{Mn}$. The carbon level is below the lower limit specified by the standard. By contrast, the amount of manganese is higher than the upper limit. This can be attributed to segregation of the two elements.

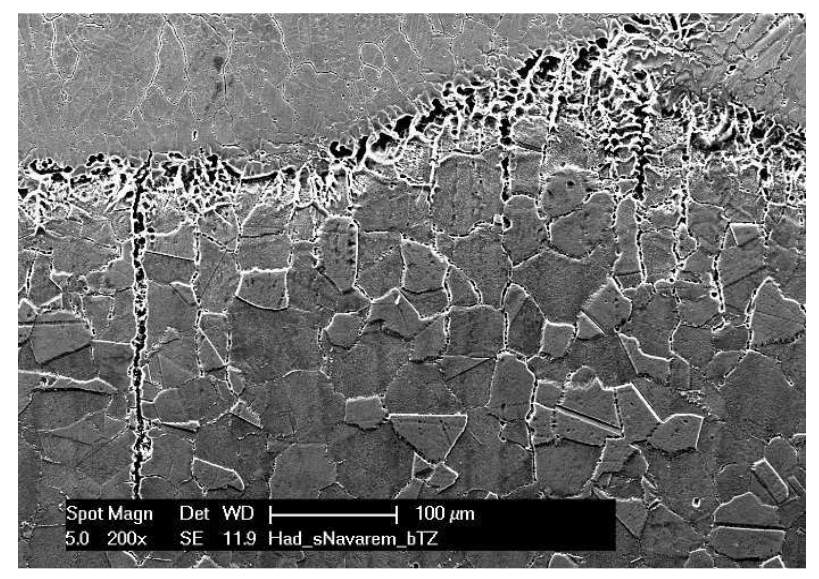

Fig. 1 Macrograph of cracks in the weld metal and a fracture in the base material.

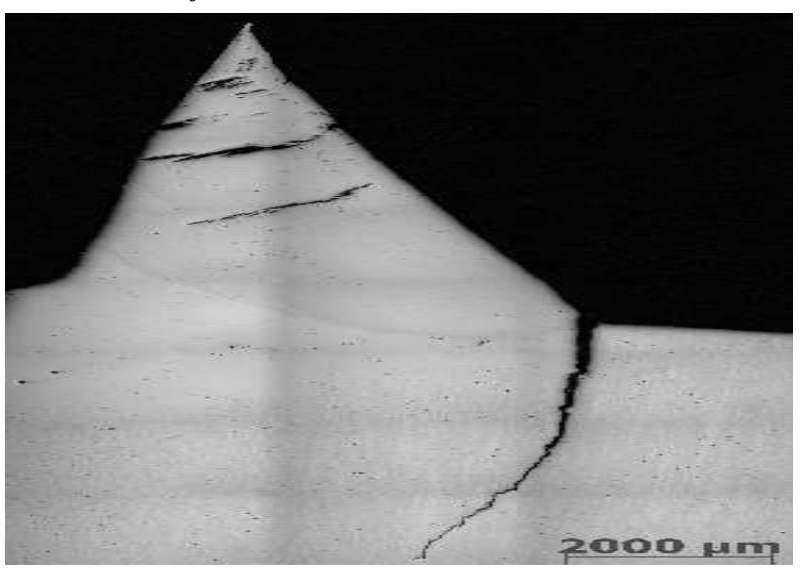

Fig. 2 Cracks in the base material, $50 \mathrm{ml} \mathrm{HCl+25} \mathrm{ml}$ $\mathrm{C}_{2} \mathrm{H}_{6} \mathrm{O}+0.1 \mathrm{ml} \mathrm{H}_{2} \mathrm{O}_{2}$.

Tab. 1 Chemical composition of X120Mn12 steel.

\begin{tabular}{|c|c|c|c|c|c|}
\hline C [wt.\%] & Si [wt. \%] & Mn [wt.\%] & P [wt.\%] & S [wt.\%] & Cr [wt.\%] \\
\hline $1.10-1.30$ & $0.30-0.50$ & $12.0-13.0$ & $\max .0 .100$ & $\max .0 .040$ & $\max .1 .50$ \\
\hline \multicolumn{6}{|c|}{ [ab. 2 Results of chemical analysis [7]. } \\
\hline C [wt.\%] & Si [wt.\%] & Mn [wt.\%] & P [wt.\%] & S [wt.\%] & $\mathrm{Cr}[w t . \%]$ \\
\hline 0.991 & 0.403 & 13.5 & 0.0193 & - & 0.487 \\
\hline
\end{tabular}

Microstructure observation was another step in the investigation. When analysing the microstructure, one can refer to the $\mathrm{Fe}-\mathrm{C}-\mathrm{Mn}$ equilibrium diagram for $13 \%$ manganese level, which is shown in Fig. 3. At higher temperatures, homogeneous austenite is present in the entire cast part. When temperature decreases very slowly below $\mathrm{A}_{\mathrm{cm}}$, binary carbides $(\mathrm{Fe}, \mathrm{Mn})_{3} \mathrm{C}$ precipitate as envelopes around austenite grains. In addition, the carbides often forms in interdendritic regions. They may also grow as needles into the austenite phase. The silicon content and the time at temperature play an important role here. Silicon reduces solubility of carbon in austenite, leading to precipitation of carbides. At silicon levels above approx. $0.8 \%$ wt., carbides grow more rapidly. The steel then exhibits a behaviour which is normally associated with higher levels of carbon. By contrast, at less than $0.3 \%$ wt. $\mathrm{Si}$, the temperature of carbide formation may decrease. Eventually, carbides may take the form of needles within austenite grains. The longer the time at temperature, the greater the number of needles. The needles grow from the phase interface between austenite and carbide envelopes
$[2,3,4]$. As temperature decreases further $\left(700\right.$ to $\left.500^{\circ} \mathrm{C}\right)$, some austenite in regions adjacent to the carbide envelopes may decompose into very fine pearlite. Between 600 and $450^{\circ} \mathrm{C}$, the carbide phase may grow in interdendritic spaces, in a manner similar to the above description. The growth of carbides, together with austenite decarburization, may lead to partial martensitic transformation. The mechanism is associated with the effect of the carbon level on the Ms temperature and the effect of the content of carbon in the matrix on stacking fault energy (SFE) $[2$, $3]$. It follows from the above explanation that the resultant microstructure of austenitic manganese steels depends primarily on the rate of cooling of the melt in a mould and the chemical composition of the melt.

Segregation bands were found using an optical microscope, see Fig. 4. The micrograph on the left was taken at $25 \times$

magnification. The detail on the right was taken at $500 \times$. This occurrence is definitely undesirable, as the steel should possess fully-austenitic microstructure, without 
carbide precipitates if possible. Using EDX, increased levels of manganese and carbon were found in these bands. Manganese and carbon segregation has led to formation of complex carbides in these regions. The material fractured in one of these segregation bands, as evidenced by Fig. 5, which shows two fracture locations in the base material where the crack follows the carbide segregation bands. The micrographs were taken at $500 \times$ magnification. This segregation definitely could not have formed during welding. It formed after the steel had been poured. To remove it, the cast steel should have been solution annealed.

In addition to the segregation bands, many pearlite colonies were found, as illustrated in Fig. 6, left. The micrograph on the right in Fig. 6 shows another undesirable phase: carbides in the form of envelopes along austenite grain boundaries and needles emanating from the envelopes or existing within austenite grains. The micrograph was taken at $1000 \times$ magnification. Microhardness was measured to confirm the presence of pearlite colonies.

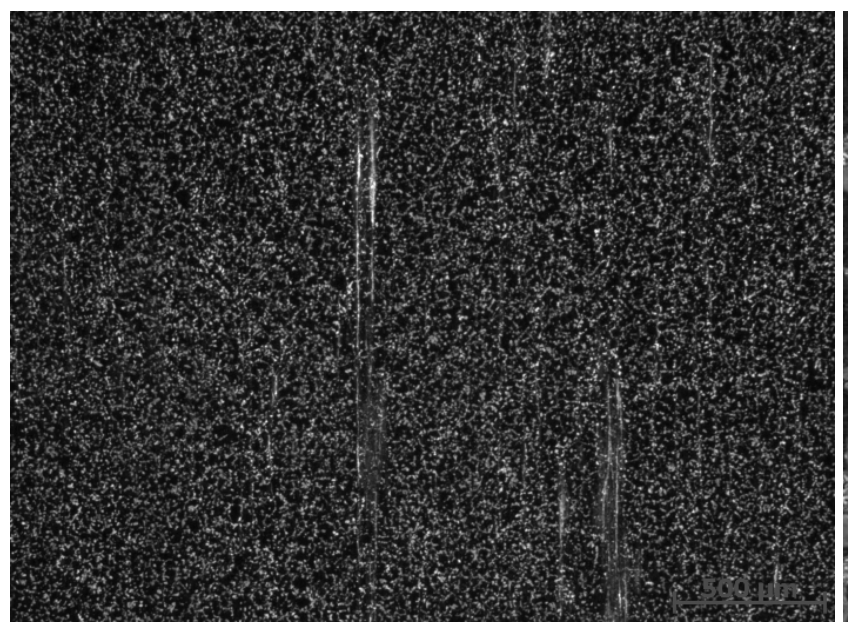

Fig. 4 Segregation bands in the base material, Klemm I.
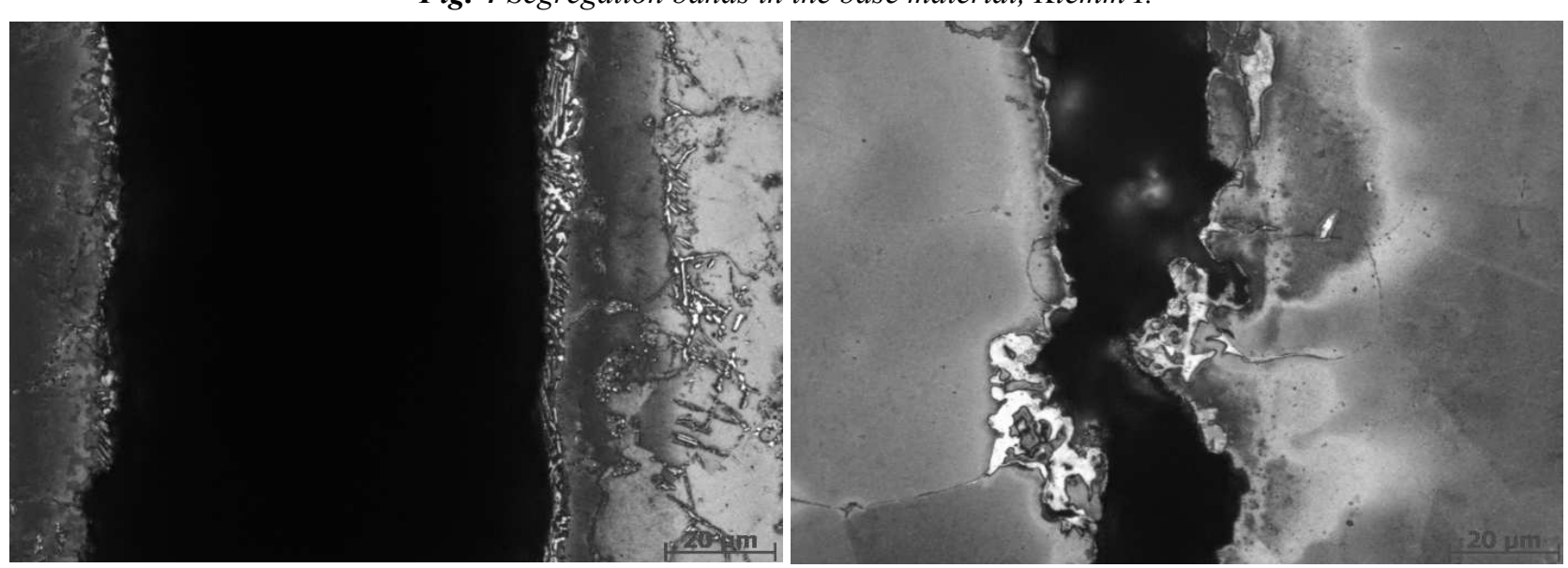

Fig. 5 Segregation bands around a fracture in the base material, Klemm I.
In an attempt to remove all the above-described microstructural heterogeneities, solution annealing was performed. The sequence comprised heating to $1050^{\circ} \mathrm{C}$, holding for 1 hour and subsequent water quenching [7]. The specimen was wrapped in a special protective foil to prevent decarburization. The solution-annealed microstructure is shown in Fig. 7. The micrographs were taken at $100 \times$ and $200 \times$ magnification. Microstructural
Their microhardness was $543 \pm 96.5$ HV 0.01. The microhardness of austenite grains was $311 \pm 45.5 \mathrm{HV} 0.01$.

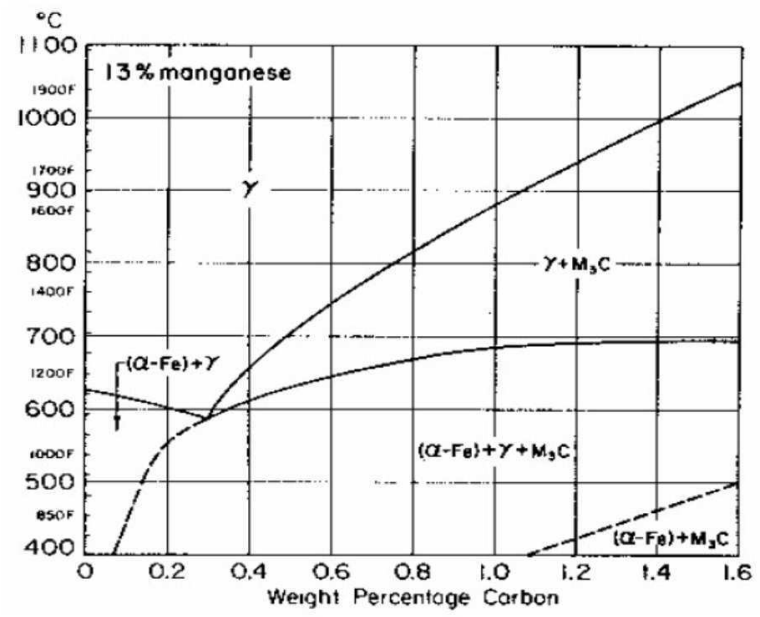

Fig. 3 Section through the Fe-C-Mn ternary diagram for $13 \% \mathrm{Mn}[8,9]$.

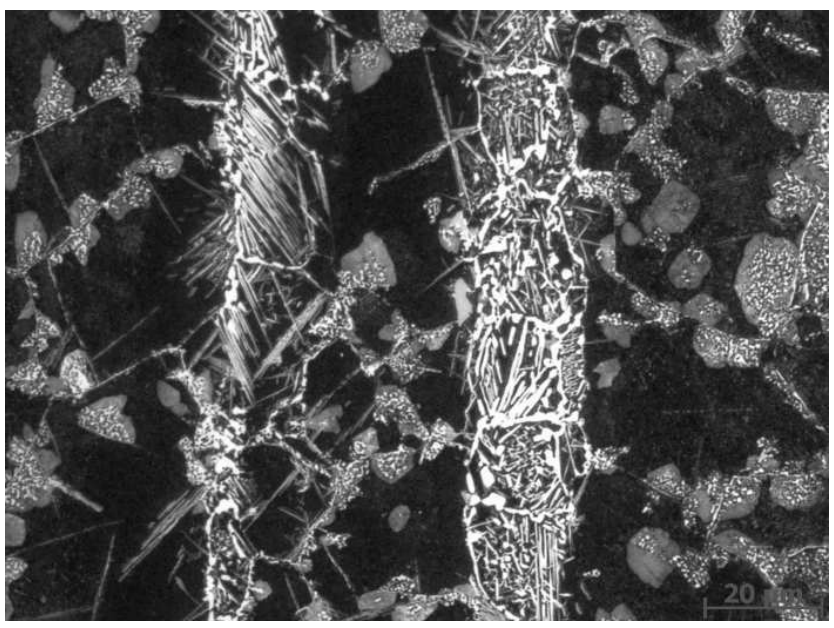

heterogeneities were successfully removed by this process. The result was an austenitic structure with a small amount of carbides along grain boundaries. However, the time at temperature proved longer than necessary, given the small size of the specimen, which was evidenced by the fact that the austenite grain had coarsened. The initial G6 size increased to G4. This negative effect could be avoided if the annealing time were shorter. 

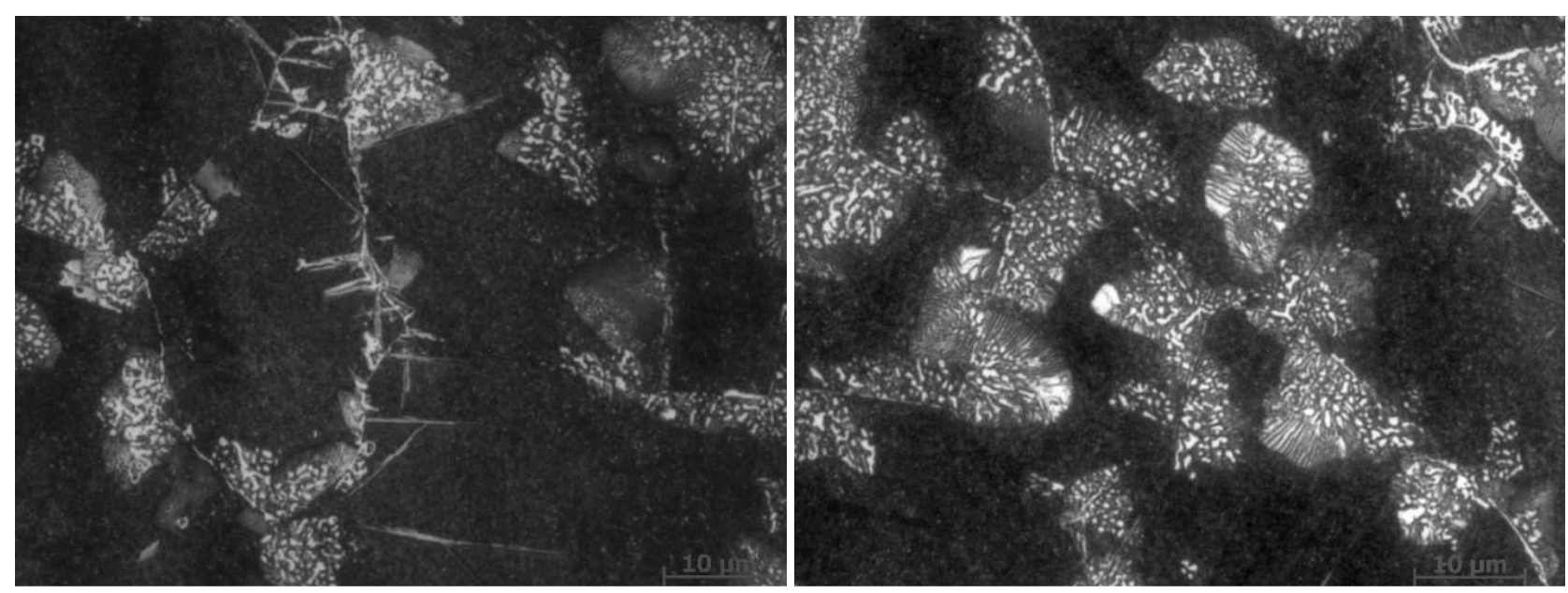

Fig. 6 Pearlite colonies and carbides within and along the boundaries of grains, Klemm I.
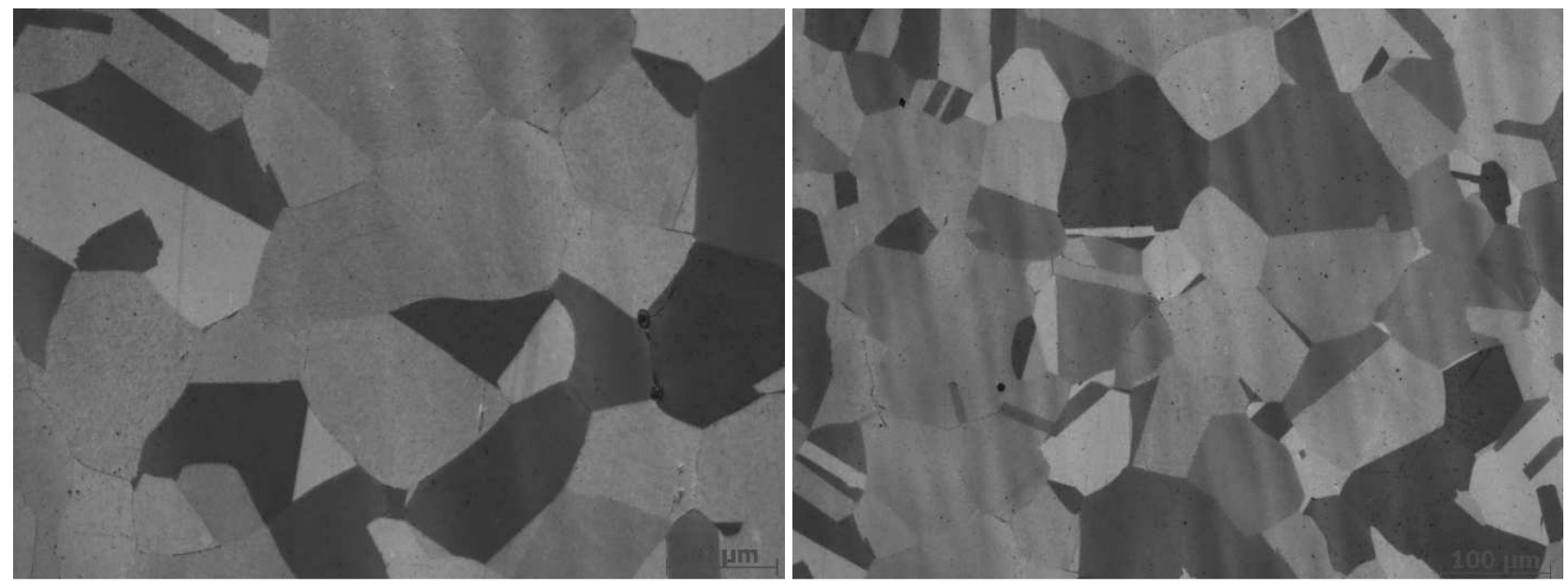

Fig. 7 Post-anneal microstructure, nital.

The second section of this contribution describes a search for a suitable etchant for this steel with heterogeneous microstructure. The following reagents are recommended for etching manganese steels: nital, picral, cyclic etch, Villela's reagent and boiling alkaline sodium picrate [3]. The following reagents were actually used in this experiment: Adler's reagent, $50 \mathrm{ml} \mathrm{HCl}+25 \mathrm{ml} \mathrm{C}_{2} \mathrm{H}_{6} \mathrm{O}$ $+0.1 \mathrm{ml} \mathrm{H}_{2} \mathrm{O}_{2}$ [6], Klemm I, Murakami's solution, nital and Vilella's reagent. The micrographs below were taken at $1000 \times$ magnification.

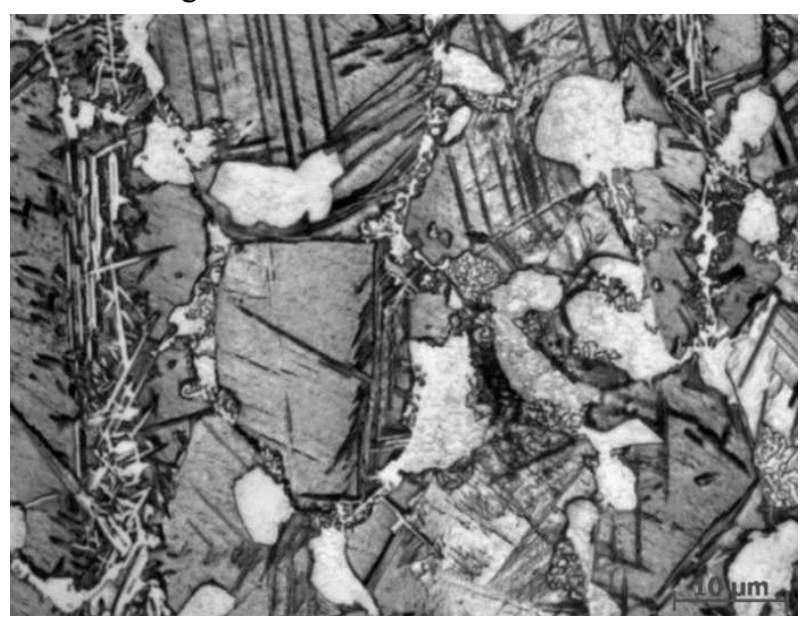

Fig. 8 Microstructure upon etching with Adler's reagent

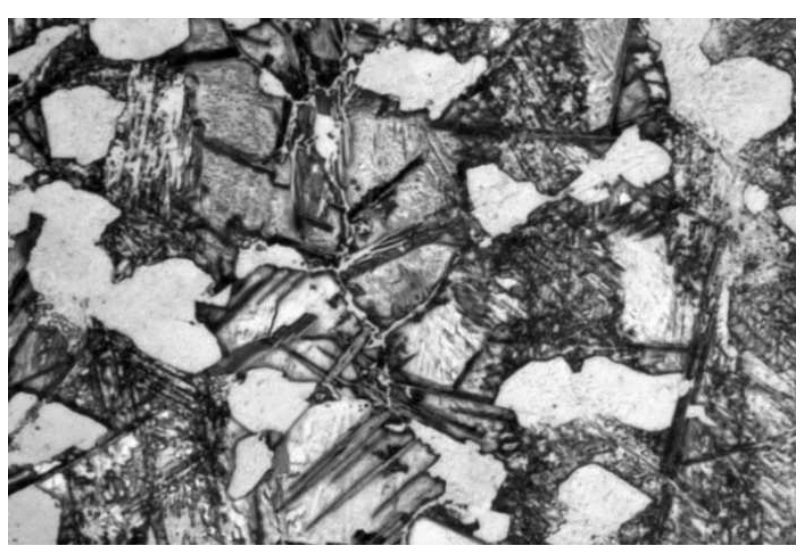

Fig. 9 Microstructure after etching with $50 \mathrm{ml} \mathrm{HCl}+25$ $m l \mathrm{C}_{2} \mathrm{H}_{6} \mathrm{O}+0.1 \mathrm{ml} \mathrm{H}_{2} \mathrm{O}_{2}$.

Adler's reagent is recommended for etching highalloy and corrosion-resistant steels and cobalt and nickel alloys [10]. As seen in Fig. 8, this etchant highlighted austenite grains, carbides along grain boundaries and carbide needles in the grain interior. Pearlite colonies were revealed incompletely. A solution that consists of $50 \mathrm{ml} \mathrm{HCl}$ $+25 \mathrm{ml} \mathrm{C}_{2} \mathrm{H}_{6} \mathrm{O}+0.1 \mathrm{ml} \mathrm{H}_{2} \mathrm{O}_{2}$ is excellent for revealing fully-austenitic microstructure [6]. A microstructure revealed using this etchant is shown in Fig. 9. Almost all microstructural constituents were highlighted, except for 
pearlite colonies. Klemm I is used for etching unalloyed or low-alloy steels, cast iron, manganese steels and zinc and its alloys [10]. It was chosen for its ability to highlight manganese segregation. The result is shown in Fig. 10. The shade of colour of the segregation band differs from the surroundings, probably due to an oxide film. With this reagent, the other microstructural constituents became visible as well. Murakami's reagent is mostly used for etching tungsten, tungsten-nickel alloys and for chromium steels [10].

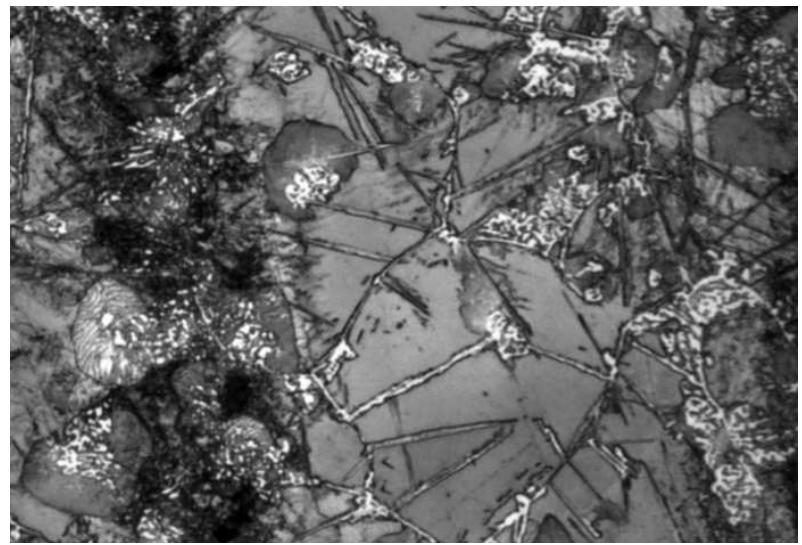

Fig. 10 Microstructure revealed by etching with Klemm I.

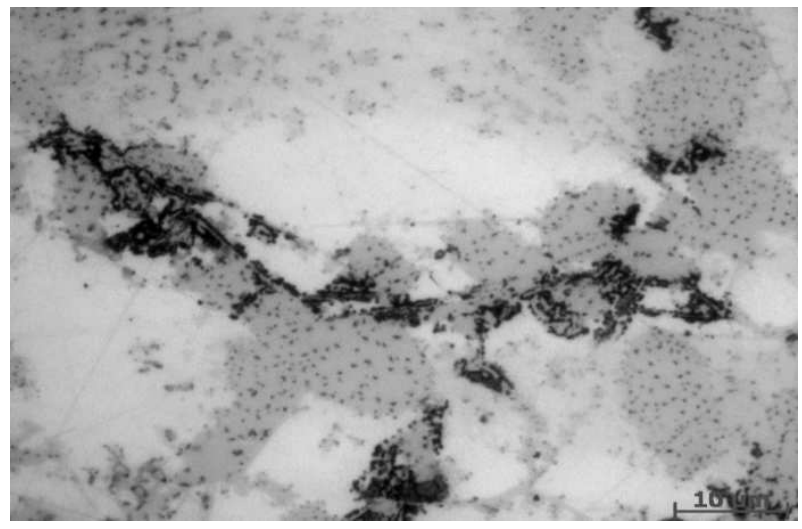

Fig. 11 Micrograph after etching with Murakami's reagent

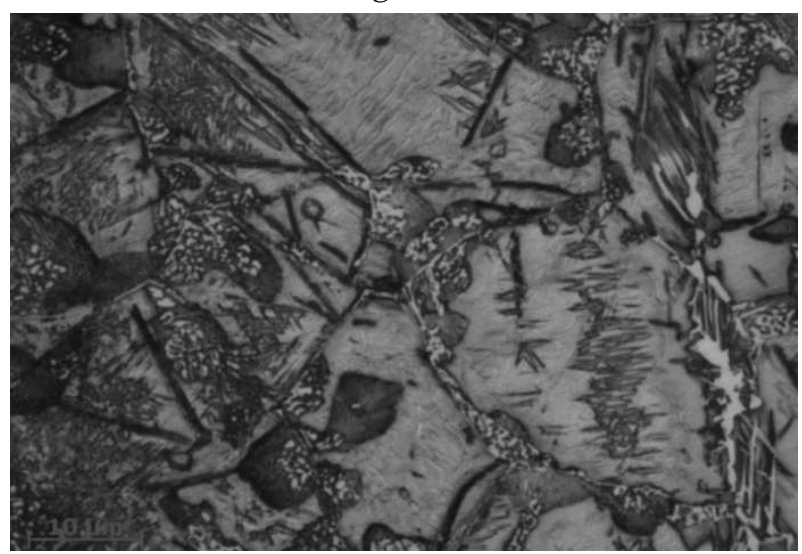

Fig. 12 Microstructure upon etching with nital

The reason for choosing this etchant was the ability to reveal chromium carbides, Fig. 11. The etch highlighted grain boundary regions with carbides. However, they were identified by EDX analysis as manganese carbides and not chromium carbides. The grey regions were probably pearlite colonies. Nital is the most commonly-used etching reagent for steels. Most often, these are carbon and low-alloy steels. A nital-etched microstructure is shown in Fig. 12. All microstructural constituents were revealed successfully. However, the use of nital on this steel leads to an oxide film. The film can be removed by swabbing with or immersing in $10 \% \mathrm{HCl}$ solution [3]. Vilella's reagent is used for etching ferritic chromium steels, austenitic chromium-nickel steels and austenitic cast steels [10]. An example of a microstructure etched with this reagent is shown in Fig. 13. Except for poorly-resolved pearlite colonies, all microstructural constituents are visible $[11,12,13]$.

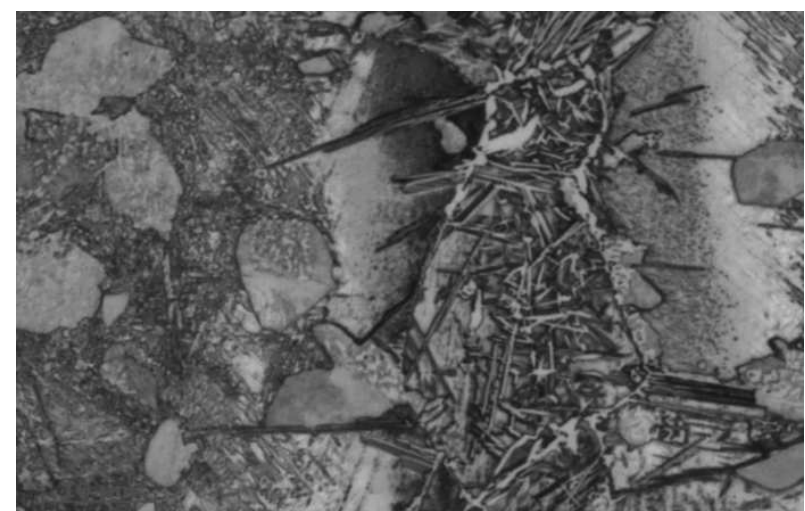

Fig. 13 Microstructure revealed by etching with Vilella's reagent.

\section{Conclusion}

This contribution was divided into two sections. The first one dealt with identifying the cause of fracture in a ring, which fractured after weld surfacing. First, the weld joint, the weld metal and the heat-affected zone (HAZ) were inspected. As part of the inspection of the weld joint, a depth profile of microhardness was measured across the weld metal and the base material. The resultant plot was without abrupt variations. In the HAZ, no grain coarsening or significant negative changes in terms of phases were detected. However, several transgranular cracks were found beneath the overlay. In this region, chemical analysis showed $1.56 \%$ chromium and $0.74 \%$ nickel. It suggests that these cracks formed in the course of welding. Cracks were also detected in the weld metal. The weld metal was found to contain much less nickel than the recommended type of filler wires for surfacing. Therefore, it can be deduced that the prescribed welding procedure was not followed. As a consequence, cracks formed in the weld metal and in the region beneath the weld overlay. Although it is certain that these deficiencies contributed to fracturing in the base material, its main cause was associated with the condition of the base material itself.

Chemical composition of the base material was measured by means of GDOES. The values met the standard, except for two elements: carbon and manganese. The carbon level was below the lower limit specified by the standard. By contrast, the manganese content exceeded the level prescribed by the standard. Segregation of these elements is responsible for this discrepancy. Conspicuous 
segregation bands were found in the base material by observation under an optical microscope. Using EDX, increased levels of manganese and carbon were found in these bands. In these regions, segregation of manganese and carbon produced complex carbides. The weldment fractured due to severe microstructural heterogeneities and due to high residual stress caused by the weld. In addition to the segregation bands, numerous pearlite colonies were found in the microstructure, as well as carbides in the form of envelopes along austenite grain boundaries and needles emanating from the envelopes or existing within austenite grains. All these heterogeneities are definitely undesirable, as the steel should possess fully-austenitic microstructure, without carbide precipitates if possible.

In an attempt to remove all the above-described microstructural heterogeneities, solution annealing was performed. The sequence comprised heating to $1050^{\circ} \mathrm{C}$, holding for 1 hour and subsequent water quenching. To prevent decarburization, the specimen was wrapped in a special protective foil. This process successfully removed the microstructural heterogeneities. The result was an austenitic microstructure with a small amount of carbides along grain boundaries. Another consequence of this heat treatment was austenite grain coarsening: from G6 to G4. The reason was the small size of the specimen. This negative effect of solution annealing could be avoided by using shorter time at temperature.

The second section of this paper explored etching of Hadfield steel. Some etching reagents from the literature and authors' experience were put to test. These included: Adler's etchant, $50 \mathrm{ml} \mathrm{HCl}+25 \mathrm{ml} \mathrm{C}_{2} \mathrm{H}_{6} \mathrm{O}+0.1 \mathrm{ml}$ $\mathrm{H}_{2} \mathrm{O}_{2}$, Klemm I, Murakami's solution, nital and Vilella's reagent. The one which proved best for this heterogeneous microstructure was nital. Although it produced an oxide film on the surface, it revealed the microstructure correctly. This undesired colour-etching effect can be eliminated by taking a black and white photograph under optical microscope. Alternatively, the tint can be removed using a $10 \% \mathrm{HCl}$ solution. An excellent method of highlighting the above-described segregation bands is colour etching with Klemm I.

\section{Acknowledgement}

This paper was prepared on the basis of project no. SGS2016-036 Analysis, development and modification of manufacturing technology in volume processing of advanced materials used in energy machinery, transport equipment and related engineering applications.

\section{References}

[1] KUZIČKIN, D., FREMUNT, P., MÍŠEK, B. (1988). Konštrukčné ocele tvárnené a na odliatky. Bratislava: Alfa, 1988.

[2] VOREL, I. (2013). Ověření možnosti nekonvenční výroby otěruvzdorné Mn oceli. Plzeň. Diploma thesis. UNIVERSITY OF WEST
BOHEMIA. Thesis supervisor: Ing. Miroslav Hála, CSc.

[3] KUYCAK, S. (2004). Austenitic Manganese Steel Castings, Metallography and Microstructures, Vol 9, ASM Handbook, ASM International, 2004, pp. 701-708.

[4] SUBRAMANYAM, D.K. (2005). ASM Handbook: Properties and Selection: Irons, Steels, and High Performance Alloys, Specialty Steels and Heat-Resistant Alloys, Austenitic Manganese Steels. 10th ed. Materials Park, OH: ASM International, 2005, 1274 - 1302. Volume 1.

[5] DARIDA, J. (2013). Analýza struktury Hadfieldovy oceli v závislosti na deformačním zatěžování. Brno: Brno University of Technology, Faculty of Mechanical Engineering, 2013. 73 pages. Bachelor thesis supervisor: Ing. Lenka Klakurkova, Ph.D.

[6] PRŮCHA, V. et al. (2017). Characterization of Microstructure of Hadfield Steel. In: Solid State Phenomena. Trans Tech Publications, 2017. pp. 265-270.

[7] KŘÍŽ, A., VNOUČEK, M. (2018). Analýza kroužku po navaření. Technical report No. 49. Department of Material Science and Technology, Plzeň.

[8] Metals Handbook, Vol. 8. Metallography, Structures and Phase Diagrams. ASM Metals Park Ohio, 1973

[9] DUŠEK, M. (2007). Tepelné zpracování 12\% Mn oceli. Plzeň. Bachelor thesis. UNIVERSITY OF WEST BOHEMIA. Thesis supervisor: Ing. Václav Kraus, CSc.

[10] PETZOW, G. (ed.) (1999).. Metallographic etching: techniques for metallography, ceramography, plastography. ASM international, 1999.

[11] KUČEROVÁ, L., JIRKOVÁ, H., MAŠEK, B. (2016). Influence of Nb Micro-alloying on TRIP Steels Treated by Continuous Cooling Process. In: Manufacturing Technology, Vol. 16, No. 1, pp. 145-149.

[12] P. HANUS, E. SCHMIDOVÁ. (2016). Influence of the welding process on the martensitic and dual phase high strength steels. In: Manufacturing Technology, Vol. 16, No. 4, pp. 702-707.

[13] KUČEROVÁ, L., BYSTRIANSKÝ, M., JENÍČEK, Š. (2017) The Effect of Annealing Temperature on Microstructure and Mechanical Properties of Lightweight Steel with Increased Aluminium Content. In: Manufacturing Technology, Vol. 17, No, 6, pp. 881-887. 